- Communication-

\title{
SERS Studies of Cytochrome c Immobilized on Modified Silver Electrode
}

\author{
Daisuke HOBARA, Katsumi NIKI* and T. M. COTTON ${ }^{\dagger}$
}

Received February 12, 1993 ; Accepted April 12, 1993

\begin{abstract}
1 INTRODUCTION
Surface-enhanced Raman scattering (SERS) and Surface-enhanced resonance Raman scattering (SERRS) are powerful methods in the studies of biomolecules. Hildebrandt and Stockburger ${ }^{1)}$ have shown that cytochrome c directly adsorbed on the silver electrode at a negative potential $(-0.4$ V vs. SCE) exhibits the six-coordinated low spin (6cLS) state which is the same as that in the solution. On the other hand, the adsorption at a positive potential $(+0.1 \mathrm{~V})$ gives rise to a mixture of five coordinated high spin (5cHS) and 6cLS configurations. Niki et al. ${ }^{2)}$ have shown that cytochrome c adsorbed on a roughened silver electrode is displaced by bis(4-pyridyl) disulfide (4PyS) on which cytochrome $c$ is immobilized. SERS signals of this electrode excited at $514.4 \mathrm{~nm}$ are almost identical to those of the 4-PyS modified electrode and no response from cytochrome $\mathrm{c}$ is obtained.

In the present work, we have characterized the oxidation, coordination and spin states of cytochrome $c$ immobilized on the 4-PyS modified gold and silver electrodes.
\end{abstract}

\section{EXPERIMENTAL}

Horse heart cytochrome $c$ (Type VI from Sigma) was purified chromatographically.

4-PyS (>98\% from Aldrich) was used

* Department of Physical Chemistry, Yokohama National University, Tokiwadai, Hodogaya-ku, Yokohama 240, Japan.

† Department of Chemistry, lowa state University, Ames, Iowa 50011 U.S.A.

Key Words: Cytochrome c, SERS, Surface Modifier without further purification. The gold and silver electrodes were mechanically polished by $0.05 \mu \mathrm{m}$ alumina powder followed by an ultrasonic cleaning in purified water. The electrodes were roughened by oxidationreduction cycle (ORC) in $0.1 \mathrm{M} \mathrm{KCl}$ aqueous solution. The adsorption of both 4-PyS and cytochrome $\mathrm{c}$ on gold and silver electrodes were made by the film transfer technique. The samples were excited by the $\mathrm{Kr}^{+}$laser beam (Coherent Innova 100). Raman spectra were obtained by OMA III Raman system (EG\&G model 1421, model 1460). The potential measurements were carried out in a quartz cell filled with $30 \mathrm{mM}$ phosphate buffer solution of $\mathrm{pH}$ 7.0. All potentials were referred to SCE.

\section{RESULTS AND DISCUSSION}

Figure 1 represents the SERS spectrum (excitation wavelength is $647.1 \mathrm{~nm}$ ) of the 4-PyS modified gold electrode on which cytochrome $c$ is immobilized. The SERS signals are almost identical to those of the 4-PyS modified gold electrode. Whereas, the SERRS spectrum of the silver electrode excited at $413.1 \mathrm{~nm}$ gives rise to the signals of cytochrome $c$, which is immobilized on the 4-PyS modified silver electrode, and no SERS signals of 4-PyS are observable (Fig.2). Since the SERS, is limited to molecules or functional groups located at distances ranging up to $0.5 \mathrm{~nm}$ from the electrode surface, the Raman signals of cytochrome $c$ are probably due to the resonance Raman effect with an electronic transition of cytochrome $c$ at the $\gamma$-peak. 


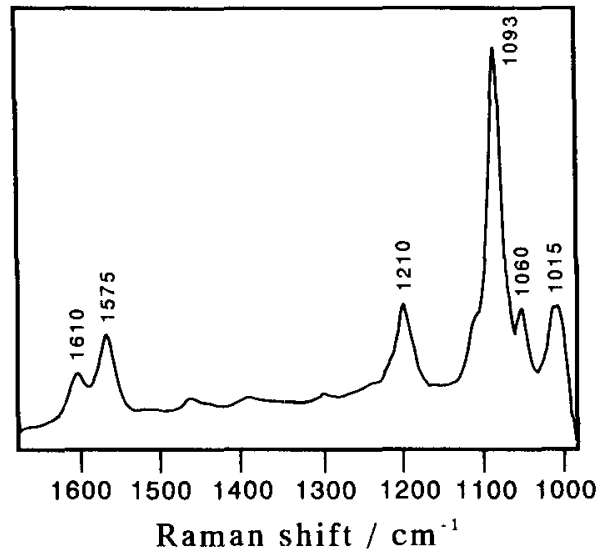

Fig. 1 SERS spectrum of cytochrome $c$ adsorbed on 4-PyS modified gold electrode at open circuit potential (excitation wavelength : $647.1 \mathrm{~nm}$ ).

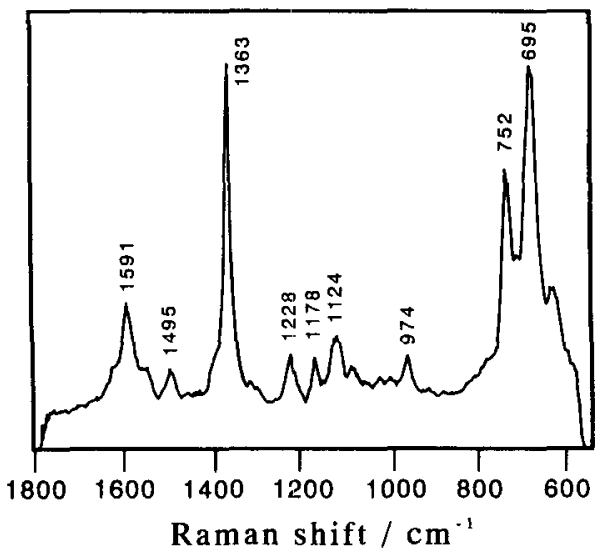

Fig. 2 SERRS spectrum of cytochrome $c$ adsorbed on 4-PyS modified silver electrode at $-100 \mathrm{mV}$ (excitation wavelength : $413.1 \mathrm{~nm}$ ).

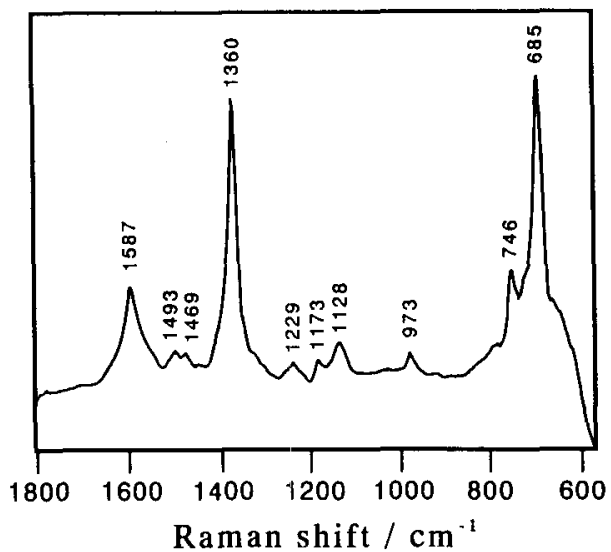

Fig. 3 SERRS spectrum of cytochrome $c$ adsorbed on a bare silver electrode at $-400 \mathrm{mV}$ (excitation wavelength : $413.1 \mathrm{~nm})$.

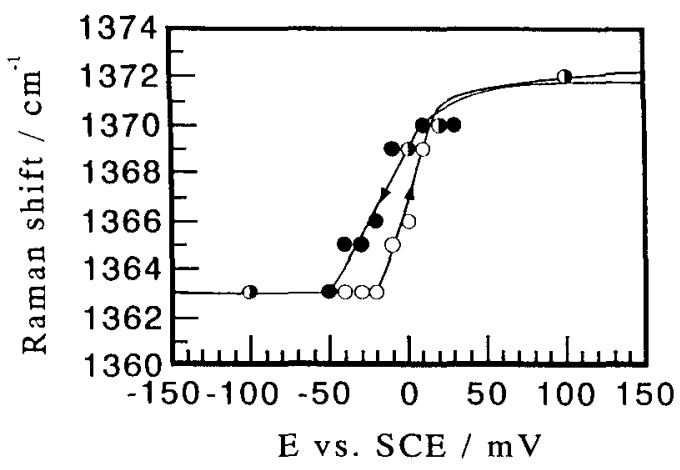

Fig. 4 Potential dependence of the marker band ( $\nu 4$ mode) of cytochrome $\mathrm{c}$ adsorbed on 4-PyS modified silver electrode. ( $\bigcirc$ : forward potential scan, $:$ reverse potential scan)

The conformation of the cytochrome c adsorbed directly to silver electrode is monitored by the shift of the marker band, $\nu 3$, and is a mixture of $6 \mathrm{cLS}\left(1493 \mathrm{~cm}^{-1}\right)$ and $5 \mathrm{cHS}\left(1469 \mathrm{~cm}^{-1}\right)$ states as show in Fig. 3. However, the spectrum represented in Fig. 2 reveals that cytochrome c immobilized on the 4-PyS adsorbed layer is in the $6 \mathrm{cLS}\left(1495 \mathrm{~cm}^{-1}\right)$, which is the same as the native form in the solution. The formal potential of cytochrome c immobilized on the 4-PyS modified silver clectrode can be estimated from the midpoint of the shift of the marker band, $\nu 4$, at 1372 $\mathrm{cm}^{-1}$ for the oxidized form and $1363 \mathrm{~cm}^{-1}$ for the reduced form (Fig.4). The estimated formal potential agrees quite well with the formal potential determined by the UV-vis electroreflectance method ${ }^{33}$. In both cases, the hysteresis was always observed and this is probably due to the slow equilibrium of the conformational change of the protein structure.

\section{REFERENCE}

1) P.Hildebrandt and M.Stockburger, Biochemistry, 28, 6710 (1989)

2) K.Niki, Fan Ke-Jun, I.Satake, K.Ueda, H.Akutsu, Redox Chemistry and Interfacial Behavior of Biological Molecules, Plenum Press, New York, p. 125 (1988)

3) C.Hinnen, R.Parsons, K.Niki, J.Electroanal.Chem., 147, 329 (1983) 